\title{
MICROSTRUCTURAL STUDY OF TIN OXIDE FILMS OBTAINED BY SPRAY PYROLISIS
}

\author{
M. Tena-Rico ${ }^{1}$, M. Miki-Yoshida ${ }^{1,2}$ and F. Paraguay-Delgado ${ }^{1}$
}

(1) División de Física y Química de materiales, Centro de Investigación en Materiales Avanzados, Miguel de Cervantes 120, Chihuahua, Chih., CP31109, México.

(2) Texas Materials Institute, University of Texas at Austin, Austin, Texas, 78712, USA.

Tin oxide in its ceramic form has been studying for many years back with the purpose of using it like a gas sensor, in this work we used this material as thin film with platinum and silver particles for the same aim [1]. The restlessness of this investigation was born, after making a study within the city of Chihuahua in which were stops indices of death and poisoning; due to gas flights. The detection technique which they use these gas sensors, consists of a semiconductor between two metal electrodes by means of which the conductance to a certain temperature and constant humidity is moderate.

To obtain films we used simple and reproducible spray pyrolysis technique, the started solution was $0.05 \mathrm{M}$ dilution of tin tetrachloride in methanol, the deposition temperature were $635 \mathrm{~K}$ and $775 \mathrm{~K}$.

TEM bright field images of tin oxide film was nanocristalline and that their structure corresponded to the tetragonal Cassiterite system. Morphology were analyzed by scanning electron microscopy, it is shown that crystalline agglomerate in round shaped grains. Film thickness was obtained by reflectance measurement in F-20 fibber optic based system. Thickness varies as a function of doped percentage parameters between 200 to $400 \mathrm{~nm}$. We focus study two samples SM12 $(635 \mathrm{~K})$ and SM14 $(775 \mathrm{~K})$, sample for low deposition temperature was annealing at $775 \mathrm{~K}$ for $4 \mathrm{H}$. then it became nanocristalline material.

The feasibility of depositing of tin oxide films has been demonstrated by a simple and reproducible spray pyrolisis technique. These results support the viability of the spray pyrolisis technique to obtain nanostructured materials.

\section{References}

\footnotetext{
${ }^{1}$ Kousuke Ihokura, Joseph Watson. Stannic Oxide Gas Sensor.
} 


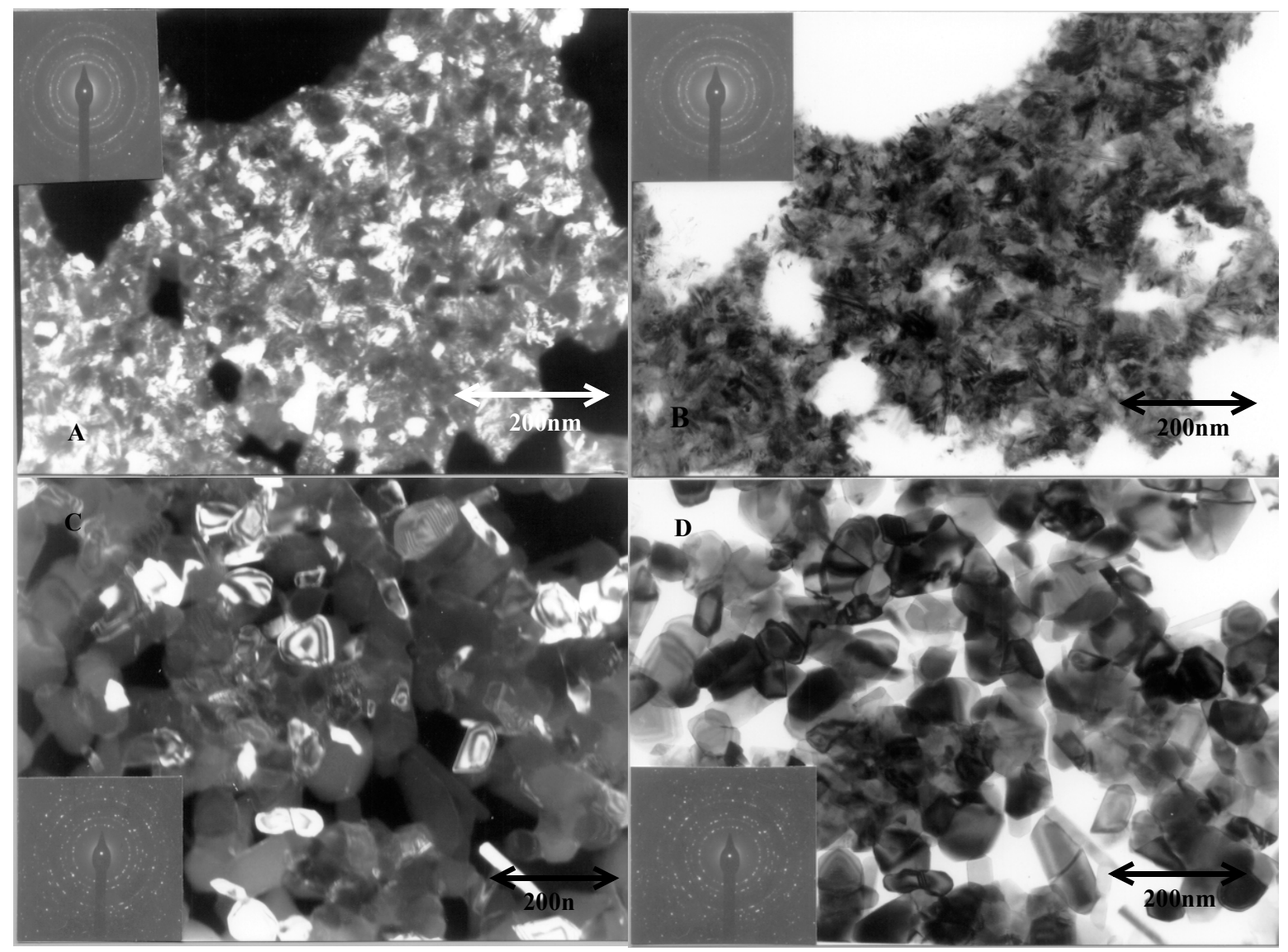

Dark field and bright field TEM micrographs of $\mathrm{SnO}_{2}$ films deposited onto glass as a function of temperature ant contents in film. a) and b) $635 \mathrm{~K}$; c) and d) $775 \mathrm{~K}$ 